\title{
LAS ESCUELAS DE BARRIADA DE BIZKAIA (1920-1937). REVISIÓN Y NUEVOS DATOS ${ }^{\alpha}$
}

\author{
Rural schools of Bizkaia (1920-1937). Review and new data
}

\author{
Karmele Artetxe Sánchez ${ }^{\beta}$
}

Fecha de recepción: 29/07/2019 • Fecha de aceptación: 02/12/2019

Resumen. El objetivo de este artículo es revisar la historiografía existente sobre las Escuelas de Barriada, creadas y promocionadas por la Diputación de Bizkaia entre los años 1920-1937, para matizar algunas cuestiones y aportar nuevos datos en torno a cuatro aspectos. En primer lugar, la cuestión de la lengua de instrucción. El uso del euskera en el aula, se vio progresivamente reducido en favor del castellano casi desde el primer momento y no suscitó la oposición del profesorado, a pesar de que gran parte de las maestras eran nacionalistas vascas. En segundo lugar, se ofrece un análisis del plan de estudios inicial, que presentaba un enfoque más pedagógico que ideológico, orientado hacia un aprendizaje más comprensivo que memorístico, hecho apreciable en las áreas de matemáticas y geometría, y que huía del adoctrinamiento político excluyente, con contenidos referidos tanto a la identidad vasca como a la española. En tercer lugar, se analiza el supuesto uso de libros de contenido político nacionalista vasco en estas escuelas, del que no hemos hallado evidencia. Y, por último, se ofrece una aproximación al tipo de profesorado que ejerció en ellas y se describe su perfil ideológico. Más del $90 \%$ del cuerpo docente estaba compuesto por mujeres, en general jóvenes, solteras, euskaldunes, católicas e ideológicamente nacionalistas vascas o simpatizantes. La investigación se centra en el análisis del periodo monárquico y primorriverista, en el que se transformó el proyecto vasquista original de estas escuelas, aunque también se presentan algunos datos y apuntes sobre la época posterior.

Palabras clave: Escuelas de Barriada; Bizkaia; Escuela vasca; Profesorado; Nacionalismo.

\footnotetext{
${ }^{\alpha}$ Este trabajo forma parte de las investigaciones desarrolladas en el marco del proyecto «Nacionalización, Estado y violencias políticas (siglos XIX-XXI)», apoyado por el Ministerio de Economía y Competitividad (HAR2017-83955-P), por el Gobierno Vasco (IT 1227-19) y por la Universidad del País Vasco/Euskal Herriko Unibertsitatea (UPV-EHU) (GIU 18/107).

в Departamento de Teoría e Historia de la Educación. Universidad del País Vasco/Euskal Herriko Unibertsitatea. Barrio Sarriena s/n, 48940 Leioa (Bizkaia). España. karmele.artetxe@ehu.eus (D) https://orcid.org/0000-0002-7252-5098
} 
Abstract. The objective of this article is to review the existing historiography on the Escuelas de Barriada (Rural Schools of Bizkaia Province, Basque Country), created and promoted by the Provincial Council of Bizkaia between 19201937, giving nuance to certain issues and providing new data on four aspects. The first of these is the question of instructional language. The use of Basque in the classroom was progressively reduced in favor of Spanish almost from the first moment and did not provoke opposition from teachers, even though many of them were Basque nationalists. Secondly, we provide an analysis of the initial curriculum, which presented a more pedagogical rather than ideological approach, oriented towards a teaching style that was more comprehensive than memory-based. This was especially appreciable in the areas of mathematics and geometry, where exclusionary political indoctrination was avoided, with content referring to both Basque and Spanish identity. Thirdly, we analyse the alleged use of books containing Basque nationalist political content in these schools, of which we have found no evidence. And finally, we offer an overview of the type of teachers that worked in these schools, including an analysis of their ideological profile: more than $90 \%$ of the faculty was composed of women, generally young, single, Basque-speaking, Catholic and ideologically sympathetic to Basque nationalism. The research focuses on the 1920-1930 period, when the Provincial Council of Bizkaia was governed by Monarchists and when the Dictatorship of Primo de Rivera began. This was the period when the original pro-Basque project of these schools was transformed. Some data and questions about the later era are also presented.

Keywords: Rural Schools; Bizkaia (Basque Country); Basque school; Teachers; Nationalism.

\section{INTRODUCCIÓN}

Las Escuelas de Barriada de Bizkaia fueron creadas a partir del año 1920 como una red escolar paralela y complementaria a la estatal. Se trató de una iniciativa a cargo de la Diputación provincial, que tenía el objetivo de hacer frente a las necesidades educativas de las zonas rurales más apartadas de Bizkaia, y que pretendía inicialmente alfabetizar al alumnado en su lengua materna (euskera o castellano, según la zona), siguiendo planteamientos pedagógicos y didácticos innovadores. Este proyecto fue investigado por Gregorio Arrien en su tesis doctoral, publicada en 1987. ${ }^{1}$ Los trabajos posteriores sobre las Escuelas de Barriada, en general, han seguido la investigación de Arrien, y en algunos casos

\footnotetext{
${ }_{1}$ Gregorio Arrien, Educación y escuelas de barriada de Bizkaia. (Escuela y Autonomía. 1898-1936) (Bilbao: Diputación Foral de Bizkaia, 1987).
} 
han optado por el elogio, eludiendo los problemas y contradicciones que existieron en el devenir de este proyecto educativo.

Recientemente la Diputación de Bizkaia, con el objetivo de dar a conocer este proyecto y mostrar su aportación histórico-cultural al desarrollo de la provincia, organizó una exposición itinerante: Escuelas de barriada de Bizkaia, 1919-1937: una decisiva actuación educativa y cultural. Asimismo, publicó el catálogo de la exposición bajo el sugerente título: Escuelas de barriada de Bizkaia, construyendo un paisaje educativo (1919-1937). ${ }^{2}$ Para completar la exposición y el catálogo, la Diputación encargó a M. Paliza, especialista en Historia del Arte (Universidad de Salamanca), una publicación monográfica sobre estas escuelas. ${ }^{3}$ Una obra que se publicó en las dos lenguas oficiales de la Comunidad Autónoma Vasca, y que según reza su título retrata una «epopeya» (sic). Paliza no añade nuevos datos sobre este proyecto educativo, ni incluye bibliografía, aunque hace una aportación interesante sobre las construcciones escolares. La autora sigue la línea propuesta por Gregorio Arrien.

Sin duda, Arrien, realizó un excelente trabajo en su momento. Se trata de una obra de imprescindible referencia, porque ofreció una visión panorámica sobre este fenómeno educativo (contexto político, número de escuelas, alumnado, la construcción, becas...), pero tras más de 30 años de su publicación, quizá sea el momento de revisar lo que sabemos y plantearnos nuevos interrogantes.

Historiográficamente ha primado una visión sobre las Escuelas de Barriada que, sin negar diferentes etapas, ha puesto el énfasis en la continuidad, puesto que a pesar de los cambios en el proyecto educativo, los centros escolares se mantuvieron tal y como fueron creados, a saber, como centros escolares rurales de nueva planta, construidos en estilo neovasco, con educación bilingüe, enmarcados en ideas pedagógicas modernas, con influencia del higienismo, con una dotación de material escolar excepcional por parte de la Diputación, participación de la comunidad rural en su construcción, etc. Sin embargo, a través de nuestra investigación, para la que hemos consultado la abundante

\footnotetext{
${ }^{2}$ Gregorio Arrien, Iñaki Pereda y Gorka Pérez de la Peña, Escuelas de barriada de Bizkaia, construyendo un paisaje educativo (1919-1937) (Bilbao: Diputación Foral de Bizkaia, 2015).

${ }^{3}$ Maite Paliza, El proyecto de las Escuelas de Barriada y su desarrollo (1919-1938). Una epopeya de la Historia de la Educación en Bizkaia (Bilbao: Gobierno Vasco, 2015).
} 
documentación existente (expedientes de asistencia, inspecciones, inventarios, informes de las maestras, proyectos de construcción, correspondencia...), hemos podido profundizar en el conocimiento de las transformaciones que se produjeron respecto al diseño original de estas escuelas y, especialmente, el impacto que provocaron las diversas políticas educativas en el alumnado y el profesorado.

A comienzos del siglo XX, Bizkaia era una provincia industrializada, pero seguía teniendo comarcas rurales en muchas zonas. ${ }^{4}$ El objetivo que perseguía el proyecto de las Escuelas de Barriada era suplir las deficiencias educativas de la provincia y superar el problema sociocultural y económico que suponía el analfabetismo. ${ }^{5} \mathrm{Si}$ tomáramos al pie de la letra este argumento, podríamos llegar a pensar que Bizkaia era una provincia con una gran tasa de analfabetismo, cuando realmente esta provincia estaba muy por debajo de la media española. En 1920 España tenía una tasa de analfabetismo del 52,2\% frente al 32,7 \% de Bizkaia. ${ }^{6}$ Aun así es cierto que 3 de cada 10 vizcaínos eran analfabetos. En este sentido las Escuelas de Barriada sí vinieron a cubrir una necesidad educativa evidente. De hecho, la necesidad se hizo más acuciante con el avance demográfico de los años 20. Es por ello que, aunque la Diputación al principio no pensaba construir más de 50 escuelas nuevas, las solicitudes superaron las expectativas, y al final se llegaron a inaugurar 125 Escuelas de Barriada en toda Bizkaia, centros en los que impartieron clase más de doscientas maestras y maestros. Este proyecto coincide con un momento en el que también el Estado estaba impulsando la creación de nuevos centros de enseñanza para hacer frente a la insuficiente red escolar y a la presión demográfica. ${ }^{7}$

En total la Diputación construyó 100 Escuelas de Barriada en el periodo principal que cubre nuestra investigación (1920-1930). Para su realización hemos consultado los expedientes de 32 de ellas, 18 creadas

\footnotetext{
${ }^{4}$ Ander Delgado, La otra Bizkaia. Política en un entorno rural durante la restauración (1890-1923) (Bilbao: UPV/EHU, 2008).

5 Pedro Zufía, Las escuelas de barriada en Vizcaya (Bilbao: Imprenta Provincial de Vizcaya, 1930).

- Paulí Dávila, La política educativa y la enseñanza pública en el País Vasco (1860-1930) (Donostia: UPV/EHU, 1995), 188.

${ }^{7}$ Ramón López Martín, «La construcción y creación de escuelas en la España del primer tercio del siglo XX», Historia de la Educación 16 (1997): 90.
} 
antes de la dictadura (Albiz, Ariatza, Arkotxa, Astelarra, Baldatika, Belendiz, Bengoetxea, Berreño, Errigoitiola, Eizaga, Laukariz, Oba, Pando, Sangrices, San Lorenzo, San Miguel de Dudea, Santa Lucia y Torkatxas) y 14 construidas entre los años 1923-1930 (Amaitermin, Andramari, Arbaiza, Arteun, Asterria, Barinaga, Botiola, Geldo, Indusi, La Calera, San Ciprian, Santa Cruz, Traslosheros y Ugarte). Consideramos que es una muestra lo suficientemente amplia y representativa, ya que abarca el $32 \%$ del total y, además, porque todas las escuelas fueron construidas y gestionadas de la misma manera desde la Diputación, y no presentan grandes diferencias entre sí. Son completamente uniformes. Todos los fondos consultados se encuentran en el Archivo Histórico de la Diputación Foral de Bizkaia (en adelante, AHFB).

Las claves de este proyecto escolar fueron tres: por un lado, se trataba de un proyecto de ampliación de la red escolar; por otro, pretendía erradicar el analfabetismo y el atraso educativo del territorio; y por último, había un motivo específico del contexto vizcaíno, ya que las Escuelas de Barriada también perseguían un fin de carácter político-cultural: crear una red de escuelas vascas donde tuvieran cabida la lengua y la identidad cultural vascas. Los centros escolares tradicionales habían sido objeto de numerosas críticas de intelectuales vascos (Belaustegigoitia, Azkue...), ya que las consideraban perjudiciales para el euskera, ${ }^{8}$ la única lengua que muchos niños utilizaban, pero que el magisterio vizcaíno, por regla general, desconocía. ${ }^{9}$ Los cambios políticos, culturales y sociales que vivió la provincia a finales del siglo XIX y principios del XX propiciaron la emergencia de un movimiento vasquista, muchas veces cercano al nacionalismo vasco, que defendía el uso de la lengua y la presencia de la cultura vasca en la escuela. Los nacionalistas vascos, sobre todo Eduardo Landeta, Luis Eleizalde y Federico Belaustegigoitia, ya antes de la creación de las Escuelas de Barriada, plantearon de forma insistente, aunque con propuestas diferentes, la necesidad de una escuela que tomara en consideración la identidad vasca, la lengua y demás aspectos relacionados con el País Vasco (historia, geografía...). Reclamaban en suma una «escuela vasca». Y estas reclamaciones tuvieron continuidad y

\footnotetext{
8 Jurgi Kintana, Intelektuala nazioa eraikitzen. R. M. Azkueren pentsaera eta obra (Bilbao: Euskaltzaindia: Real Academia de la Lengua Vasca, 2008): 311-344.

9 Joxe Garmendia, Iñaki Zabaleta e Hilario Murua, "Alfabetización en euskara en las escuelas rurales del País Vasco (1900-1939)», Historia y Memoria de la Educación 7 (2018): 201.
} 
fueron potenciadas por instituciones culturales como la Sociedad de Estudios Vascos, fundada en 1918, y por la Academia de la Lengua Vasca, creada en la misma época.

\section{EL PRIMER PROYECTO VASQUISTA}

Tras la victoria electoral nacionalista de 1917 en las elecciones provinciales, la nueva Diputación de Bizkaia, bajo los auspicios de Ramón de la Sota y Aburto, constituyó una Junta de Instrucción Pública con el objeto de estudiar la reorganización de la educación primaria en la provincia. El diputado general, había recibido una selecta educación superior en el King's College de Londres, pero anteriormente fue alumno de un colegio bilbaíno, pionero en el uso de la lengua vasca en el aula, Ikastetxea. ${ }^{10}$ De hecho, el Ikastetxea fue patrocinado por su padre, el empresario y asimismo líder nacionalista, Ramón de la Sota y Llano, lo que muestra el compromiso de ciertos miembros de la élite económica de Bizkaia en torno al uso de la lengua vasca como lengua de instrucción. En mayo de 1917 ya con el cargo de diputado general, Sota y Aburto pronunció estas palabras en torno al problema de la alfabetización de los niños y niñas monolingües vascos:

En la parte rural de Vizcaya hay una masa muy importante de población joven que no conoce el castellano, que habla simplemente el euskara; a esa juventud se le enseñan las primeras letras en castellano. Y resulta que como no entienden lo que se les enseña, salen de las escuelas sin saber leer ni escribir, es decir, han perdido el tiempo. ${ }^{11}$

La Junta de Instrucción fue dotada en 1918 con atribuciones ejecutivas, de forma que las decisiones de la misma no necesitaban el refrendo de la Diputación. A partir de entonces la Diputación delegaría en la Junta el desarrollo de los temas educativos, y se limitaría a mantener una comunicación fluida con la misma. De hecho, la Junta estaba formada por diez diputados provinciales (la mayoría nacionalistas vascos, aunque no todos, el liberal Juan Gallano también participaba), además de

\footnotetext{
10 Jurgi Kintana y Karmele Artetxe, «Ikastetxea 1896: un proyecto de colegio euskérico dirigido a la burguesía de Bilbao», Foro de Educación 25 (2018): 49-68.

${ }^{11}$ Citado en Garmendia, Zabaleta y Murua, «Alfabetización en euskara», 204.
} 
por otros seis asesores designados por la misma Diputación. El nacionalista Luis Eleizalde, licenciado en Ciencias y catedrático de Matemáticas en el Instituto de Vitoria-Gasteiz, se incorporó dos años después, al ganar en concurso público el puesto de inspector de enseñanza de la Junta.

Entre 1917 y 1919 la Junta de Instrucción Pública desarrolló un programa de subvenciones dirigido a los colegios y escuelas de Bizkaia para fomentar la enseñanza en lengua vasca, además de promover la creación de cátedras de euskera en las Escuelas Normales de Bilbao y Barakaldo, y realizar otras gestiones educativas. ${ }^{12}$ En cualquier caso, hasta 1919 esta entidad no dispuso de un gran proyecto educativo y se limitaba a mejorar lo que había. El gran proyecto llegó el 26 de noviembre de 1919 cuando el diputado Juan Gallano, de tendencia liberal autonomista, presentó en la Diputación de Bizkaia la moción para la creación de las Escuelas de Barriada cuya organización y cuerpo docente dependería de la corporación provincial.

La moción del diputado Gallano fue apoyada por los nacionalistas que vieron una oportunidad para desarrollar un proyecto escolar propio. La propuesta fue aprobada en la Diputación, y posteriormente fue desarrollada entre el propio Gallano, Landeta, Eleizalde y otras personas. La Junta de Instrucción se encargó de orientar, inspeccionar y coordinar todo el proyecto de las Escuelas de Barriada.

Fueron esta Junta y este grupo de personas, vinculadas en su mayoría al nacionalismo vasco, los que establecieron la orientación original de las Escuelas de Barriada. ${ }^{13}$ Esta sería la fase vasquista de estas escuelas. El hecho de que los nacionalistas vascos perdieran en las elecciones de 1919 el control de la Diputación de Bizkaia (que pasó a manos de la Liga Monárquica, de tendencia españolista) no interrumpió inmediatamente la fase vasquista, ya que Eleizalde y otros nacionalistas siguieron en la Junta de Instrucción Pública y desde allí trataron de dar continuidad al proyecto original, y en gran medida lo lograron, al menos durante los años 1921-1922. Pero ¿cuál era este proyecto vasquista? Siguiendo el modelo inicial recogido en el Plan y cuadros de enseñanza de las

\footnotetext{
12 Paulí Dávila e Iñaki Zabaleta. «La política educativa de las diputaciones vascas: entre proyectos y subvenciones», en Las políticas educativas en el País Vasco durante el siglo XX, ed. Pauli Dávila (Madrid: Biblioteca Nueva, 2004), 143-190.

13 Arrien, Educación y escuelas de barriada, 131-140.
} 
Escuelas de Barriada, dos eran los elementos claves: uno el modelo lingüístico, y otro, el plan de estudios. En base a la lengua se establecían dos categorías:

$1^{\circ}$. En las Escuelas de la categoría «A» se dará la enseñanza en lengua vasca, constituyendo la lengua castellana materia obligatoria de enseñanza en todos los cursos de dichas escuelas.

$2^{\circ}$. En las escuelas de la categoría «B» se dará la enseñanza en lengua castellana, constituyendo la lengua vasca materia voluntaria de enseñanza en el curso superior de dichas escuelas. ${ }^{14}$

Las escuelas de categoría «A» correspondían a los territorios de Bizkaia donde el euskera era la lengua habitual, y los de categoría «B» a los territorios en los que predominaba la lengua castellana. Esta clasificación recogida en el plan inicial se mantuvo hasta 1938, aunque con modificación de contenido según veremos. Se trataba, por tanto, de una misma escuela, con dos líneas lingüísticas, que intentaba responder a la realidad sociolingüística de cada zona de la provincia: una euskaldun, que abarcaba aproximadamente dos tercios del territorio, y la otra castellanoparlante.

Este planteamiento posibilitaba que el alumnado euskaldun pudiera alfabetizarse y recibir instrucción en su propia lengua, además de aprender la lengua castellana. Asimismo, ofrecía la oportunidad a los niños castellanohablantes de aprender voluntariamente el euskera. Hemos comprobado a través de los inventarios de las primeras escuelas de categoría A construidas en este primer periodo (Albiz, Belendiz, Laukariz, San Miguel...), que efectivamente tenían docenas de ejemplares de 3 libros en euskera: un silabario (Euskeraz irakurteko irakaspidea o bien Lenengo irakurkizunak), una aritmética (Euzkal-Zenbakistia: lenengo ikaste mallarako) y un catecismo. El resto de libros, estaban en castellano. Además, el profesorado se preocupó de que los niños de estas zonas aprendieran el castellano. Un ejemplo de ello es la carta enviada por la maestra nacionalista de San Miguel de Dudea (Amorebieta-Etxano),

\footnotetext{
14 «Plan y cuadros de enseñanza, número, orden y nombre de las asignaturas que comprende» conservado en varios expedientes de creación de las escuelas construidas entre 1920-1922 enviados al rector de la Universidad de Valladolid. Archivo Histórico de la Diputación Foral de Bizkaia (en adelante, AHFB), Sección Educación y Cultura, Subsección: Escuelas de Barriada. Por ejemplo, en el «Expediente de creación y gestión de la Escuela de Barriada de San Lorenzo» caja 25, AHFB.
} 
Julene Azpeitia, al inspector de la Diputación en 1921, dentro todavía de la fase vasquista:

[...] ruego a V. S. con todo encarecimiento me haga el favor de enviar 12 ejemplares del libro de texto adecuado para la clase superior, $12 \mathrm{idm}$, idm, para la clase media y 1 ejemplar adecuado para la clase de los alumnos más pequeños, para implantar la enseñanza de la gramática castellana en esta escuela y cumplir lo ordenado en dicha circular. ${ }^{15}$

En las escuelas de categoría «B» construidas en estos primeros años (Pando, Sangrices, Torkatxas...), hemos podido constatar que la totalidad de libros de texto estaban en castellano y que no tuvieron material alguno en euskera. Por lo tanto, el alumnado de la zona castellanohablante, aunque el reglamento inicial lo permitiera, no tuvo la opción práctica ni real de aprender la lengua vasca. Además, el profesorado destinado a estas escuelas no sabía euskera.

Por tanto, en las escuelas de categoría «A» sí empezó a funcionar una alfabetización en euskera, además de ser la lengua de uso oral en el aula. También es cierto que la Diputación no llegó a abastecer de estos tres libros a todas las escuelas de esta categoría, porque muchas veces las existencias se acabaron ${ }^{16}$ y porque, para cuando se imprimió otra tirada, el inspector Eleizalde, por orden de la nueva Diputación monárquica, ya había enviado una circular estableciendo el uso de textos en lengua castellana en todas las escuelas, con la excepción del catecismo que podía ser adquirido en lengua vasca. ${ }^{17}$. El resto de libros debían estar exclusivamente en castellano. El origen de esta prohibición reside, según cuenta Arrien, en un artículo publicado en mayo de 1921 en el periódico El

\footnotetext{
${ }_{15}$ Carta del 03.11.1921 de la maestra J. Azpeitia al inspector Eleizalde. «Expediente de creación y gestión de la Escuela de Barriada de San Miguel de Dudea», caja 3, AHFB.

${ }_{16}$ Carta del 07.01.1922 del inspector Eleizalde a la maestra de Eizaga: «Tengo el honor de comunicar a Ud. que con esta fecha se ha enviado a la librería de Sr. Arano el pedido de material que nos hace con objeto de que lo remita a Ud. dejando de enviarle por carecer de ellas las aritméticas euskéricas» «Expediente de creación y gestión de la Escuela de Barriada de Eizaga», caja 25, AHFB.

${ }_{17}$ Esta circular del 07.03.1922 del inspector L. Eleizalde resume dos circulares anteriores: una del 16.01.1922 que establecía el uso de textos en lengua castellana tanto en las escuelas de categoría «A» como «B», y otra del 09.02.1922 en la que se que se admitía que él único libro en euskera fuera el catecismo. La circular de marzo se conserva en los expedientes de creación y gestión de las primeras escuelas de barriada (Albiz, Belendiz, Bengoetxe, San Miguel de Dudea), cajas 19, 3 y 11, AHFB.
} 
Magisterio Español por Emilia Guspolcuz, en el que se denunciaba el contenido separatista y lesivo respecto al castellano de una serie de libros, que la Diputación había premiado y que supuestamente pensaba distribuir entre las escuelas primarias de la provincia, fueran o no de barriada. ${ }^{18}$ Los libros analizados por Guspolcuz son en concreto: Azijerea ta osasun-bidia de Ceferino Xemein y Ume euzkeldunen laguna de Joseba Altuna.

Los autores de estos dos libros fueron dos conocidos nacionalistas sabinianos, y algunas de las frases mencionadas por Guspolcuz eran propias de la ideología que profesaban. Guspolcuz recoge ejemplos como: «En esta lección se habla de la nación Euzcadi (Euzkadi Aberija) a todo pasto» o bien «Hay un verso que dice: Tomad el vascuence y dejad el castellano». Si bien estas obras, tanto la de Xemein como la de Altuna, se realizaron y publicaron en la provincia de Bizkaia, Arrien no aclara si realmente llegaron a ser utilizadas en las Escuelas de Barriada. Por los documentos que hemos revisado, podemos concluir que no, ya que no aparecen en los inventarios consultados, y tampoco consta que la Diputación los repartiera por sus escuelas. En la de Albiz (Mendata), en el inventario del 20 de enero de 1921, anterior a la polémica de mayo, y elaborado por la maestra nacionalista Purificación Mandiola de la que hablaremos más adelante, y con el visto bueno del alcalde, sí se listan dos libros en euskera: por un lado, Lenengo irakurkizuna de Gaztañaga, para aprender a leer y escribir, y por otro, Euskal zenbakiztia de L. Eleizalde, sobre aritmética. En San Miguel de Dudea (Amorebieta-Etxano) y Laukariz (Mungia), se repiten los dos de Albiz y el catecismo (Kristau ikasbidea). Pero no hemos hallado ninguna mención a los libros de Xemein y Altuna.

Las denuncias de Guspolcuz y otras semejantes aparecidas en la prensa provocaron que el Rector de la Universidad de Valladolid, a cuyo distrito pertenecían las escuelas del País Vasco, pidiera a la Diputación de Bizkaia modificar el plan de estudios de las Escuelas de Barriada. Por lo tanto, la polémica sobre el contenido político de unos textos que en la práctica no se usaban en las Escuelas de Barriada, trajo consigo que la Diputación, en la que ya no gobernaban los nacionalistas, decidiera abandonar definitivamente la orientación vasquista de estas escuelas,

18 Arrien, Educación y escuelas de barriada, 142-143. 
con lo que los textos no polémicos de Gaztañaga y Eleizalde no se volvieron a repartir más. En algunas de las primeras escuelas estos textos siguieron apareciendo en los inventarios de los años posteriores a 1921, hasta que se rompieron o desaparecieron. ${ }^{19}$

En este contexto general de control sobre contenidos político-culturales vascos, la Diputación, regida por la Liga Monárquica, modificó pronto el reglamento original de las Escuelas de Barriada y fijó que en las Escuelas de Barriada de categoría «A» se usara la lengua vasca como lengua oral de instrucción, pero que no se enseñara la lectura ni escritura de la lengua vasca, ni su gramática. Así que tanto el profesorado como el alumnado podían hablar en euskera, pero las asignaturas, desde el curso elemental hasta el superior, debían enseñarse en castellano. La única excepción consentida, como ya se ha mencionado, fue la doctrina cristiana, que se mantuvo en lengua vasca. Las escuelas que se abrieron entre 1922 y 1923, como la de Geldo (Zamudio) o Indusi (Dima), todavía fueron abastecidas con un catecismo en euskera, Kristau ikasbidea. Los centros construidos posteriormente, no recibieron ni siquiera esta obra.

\section{ENCUADRE PEDAGÓGICO Y PLAN DE ESTUDIOS INICIAL}

En cuanto al planteamiento pedagógico, las Escuelas de Barriada seguían en líneas generales los principios de la Escuela Nueva. La Escuela Nueva surge en Europa a finales del XIX, y se consolida en las primeras décadas del siglo XX como propuesta alternativa a la escuela tradicional. Esta nueva corriente pedagógica pone en el centro del proceso de enseñanza-aprendizaje al alumnado. Es él, el que va a aprender y va a aprender haciendo. Se trata pues de un aprendizaje experiencial y activo. Esta nueva concepción pedagógica hace que la Escuela Nueva sea paidocéntrica, respecto a la tradicional, que se presenta como magistocéntrica. ${ }^{20}$ Estas corrientes reconocían el valor del juego en el aprendizaje y la estimulación de la creatividad del niño. El pedagogo alemán

\footnotetext{
19 En Baldatika (Forua) en el inventario de 1922 aparecen 50 ejemplares, y en el de 1927 ya solo quedan 23 catecismos, aunque se menciona que están nuevos. Seguramente esto se debe a que no se utilizaban desde hacía varios años en el aula. «Expediente de creación y gestión de la Escuela de Barriada de Baldatika», caja 11, AHFB.

20 Antonio Viñao, Escuela para todos. Educación y modernidad en la España del siglo XX (Madrid: Marcial Pons, 2004), 34.
} 
Froebel (1782-1852), por ejemplo, diseñó una serie de juegos educativos que utilizó en sus escuelas y que, según los inventarios, también llegaron a las Escuelas de Barriada de Bizkaia. Este material era definido como material básico que toda Escuela de Barriada debía tener, y era la Diputación la encargada de proporcionarla.

Asimismo, se concebía que el aprendizaje no solo se realizaba en la escuela o en el aula, sino también fuera de ella. Hemos podido constatar que el alumnado daba paseos con la maestra, hacía excursiones al bosque o a la playa, para aprender Geografía, o visitaba una papelera, o iba a Bilbao a conocer empresas como los astilleros Euskalduna. Asimismo, muchas escuelas tuvieron un huerto alrededor, para plantar plantas y árboles y el castigo físico estaba prohibido. Hubo, sin embargo, alguna cuestión en la que las Escuelas de Barriada no siguieron las orientaciones de la Escuela Nueva, como en el caso de la separación por sexos, que seguía un modelo tradicional.

La inspección en sus visitas no solo se preocupaba del nivel de conocimientos y capacidades adquiridas por el alumnado, sino que también prestaba atención a la metodología empleada por el profesorado y le orientaba si era necesario. Los maestros que para el aprendizaje utilizaban métodos como la repetición o la memorización, eran corregidos por la inspección.

Los niños y las niñas eran admitidos con 6 años y el currículo que iban a seguir hasta los 13 años era bastante preciso. Por su interés para el análisis de las bases curriculares e ideológicas de estas primeras escuelas, reproducimos aquí el currículo original, que hasta ahora no se ha publicado en su integridad (hemos remarcado en negrita las materias más ligadas a cuestiones de identidad y lengua):

CATEGORIA «A» (Escuelas vascas)

Curso elemental (de seis a ocho años)

Instrucción religiosa y moral;

\section{Lectura y escritura (en lengua vasca);}

Primeros principios de Aritmética (numeración oral y escrita de enteros, las dos primeras operaciones) y de Geometría (trazado de rectas de ángulos y de la circunferencia); 
Primeros principios de Geografía (observación directa y descripción sumaria de accidentes de Geografía física al alcance de la vista);

Lengua y Gramática castellana (primer vocabulario; conjugaciones de los auxiliares; formación de oraciones sencillas);

Primeras prácticas de Higiene y de limpieza personal;

Cantos (de viva voz).

Curso medio (de ocho a diez años)

Instrucción religiosa y moral;

Lectura corriente (con explicación de las palabras y de los conceptos) escritura al dictado; lectura de manuscritos);

Primeros principios de gramática vasca (partes de la oración nociones de sufijación, primeros principios acerca del verbo);

Aritmética (las cuatro operaciones, numeración de decimales; operaciones con decimales) y Geometría (trazado y propiedades elementales de los ángulos, triángulos, polígonos y circunferencias);

Geografía (continuación y desarrollo de las primeras nociones; los puntos cardinales; las estaciones; fenómenos atmosféricos; la Geografía local; primeras nociones de Geografía general) Historia (Vizcaya y País Vasco); primeras nociones);

Ciencias físicas (primeras nociones; lecciones de cosas graduadas; el hombre, los animales, los vegetales, los minerales; fenómenos usuales estados físicos y sus transformaciones; nociones sumarias sobre las transformaciones de las primeras materias);

Preceptos y prácticas de Higiene (nociones sobre la higiene de la respiración, del alcohol, del tabaco, etc.);

Ejercicios físicos;

Solfeo (discrecional);

Trabajos de aguja (para las niñas).

Curso superior (de diez a trece años)

Instrucción religiosa y moral;

Lectura expresiva (con nociones de análisis gramatical);

Complementos de escritura y caligrafía;

Aritmética (...) y Geometría (...); 
Gramática vasca (continuación de las nociones anteriores; la conjugación, la sintaxis, el análisis gramatical y la composición);

Lengua y Gramática castellana (complementos de vocabulario; verbos irregulares; construcción de frases y periodos; ortografía);

Geografía (Complementos de las nociones anteriores; Geografía descriptiva de Vizcaya, del País Vasco, de España y de Europa: elementos de la Geografía del globo), Historia (Complementos de las nociones anteriores: Historia de España y nociones de la Historia Universal);

Ciencias físicas (Complementos de las nociones anteriores); Ciencias naturales (El hombre; descripción del cuerpo humano y las principales funciones de la vida; el reino animal; clasificaciones generales.- Id. en los reinos vegetal y mineral). Aplicaciones: a) a la agricultura (en las escuelas de la zona agrícola); b) a la industria (en las escuelas de la zona minero-fabril); c) a la navegación y a la pesca (en las escuelas de la zona marítima).

Preceptos y prácticas de higiene (Complementos y ampliaciones de las nociones anteriores);

Ejercicios físicos;

Solfeo (discrecional);

Trabajos de aguja y menaje doméstico (para niñas). ${ }^{21}$

En las escuelas de categoría «B» se especificaba que se aplicaría el mismo plan con estas únicas diferencias:

$1^{\mathrm{a}}$. Toda la enseñanza de los tres cursos se dará en lengua castellana.

$2^{\text {a }}$. La asignatura de lengua y gramática castellana del curso superior de las escuelas de la categoría «A», será sustituido en estas en análogos cursos y lugar, por la asignatura de «Lengua y gramática vascas» aunque con carácter voluntario. ${ }^{22}$

\footnotetext{
21 «Plan y cuadros de enseñanza, número, orden y nombre de las asignaturas que comprende» en la solicitud de apertura de la Escuela de Barriada de Belendiz de la Diputación de Bizkaia al Rector del distrito universitario de Valladolid de 27.11.1920, «Expediente de creación y gestión de la Escuela de Barriada de Belendiz», caja 3, AHFB.

22 «Plan y cuadros de enseñanza, número, orden y nombre de las asignaturas que comprende» en la solicitud de apertura de la Escuela de Barriada de Belendiz de la Diputación de Bizkaia al Rector del
} 
Como puede apreciarse, los contenidos referentes a la identidad nacional no son muy marcados: se menciona la enseñanza de la historia y geografía de Bizkaia y del País Vasco, pero también la de España y la de Europa, siguiendo una orientación concéntrica que va de lo más cercano a lo más lejano, sin establecer una jerarquía identitaria tajante. Es por ello que hemos optado por denominar esta fase como vasquista, puesto que respecto al modelo anterior añadía el uso de la lengua vasca y algunos contenidos curriculares referentes al País Vasco. Pero no con una visión exclusivamente nacionalista vasca. En lo demás, las materias son «neutras» y prima el enfoque pedagógico sobre el directamente ideológico.

Por otro lado, para desarrollar un currículo de estas características era necesario dotar a las escuelas de material escolar adecuado (mapas, láminas, reglas, piezas geométricas de madera, cuadernos, pizarras, esponjas, papeles de colores, juegos, termómetros, balanzas, esferas terrestres...). De todo ello se encargó la propia Diputación, y los inventarios de cualquier escuela son buena muestra de ello. Es apreciable el esfuerzo que se hacía en la formación matemática, en geometría y aritmética, con abundante material para un aprendizaje más compresivo; también destacaba la formación religiosa: los catecismos, en general, no se compartían, como se hacía con los demás libros, ya que cada niño tenía el suyo. En cuanto a la formación histórico-geográfica, en la práctica no resultaba especialmente vasca, ya que según los inventarios que hemos consultado los únicos mapas físicos y políticos que se usaban eran los de España y los de Europa, y en cuanto a los manuales solo hemos encontrado referencias a manuales de Historia de España. Este dato contrasta con el plan de estudios recogido anteriormente en el que se menciona en los curso medio y superior una formación en Geografía e Historia de Bizkaia, del País Vasco, de España y de Europa. Pero según los inventarios consultados, en este primer periodo vasquista no constan mapas, ni manuales de Historia o de Geografía referentes a Bizkaia o el País Vasco.

El logro principal de esta fase vasquista sería, por tanto, la creación de unas escuelas que alfabetizaban e instruían en la lengua materna del

distrito universitario de Valladolid de 27.11.1920, «Expediente de creación y gestión de la Escuela de Barriada de Belendiz», caja 3, AHFB. 
alumnado, ya fuera ésta el castellano o el vasco. De hecho, durante un breve periodo, en las escuelas de categoría «A» se usaron libros y materiales en euskera, aunque sin llegar a incluir mapas o manuales de historia vasca. Los posteriores proyectos políticos, bien fueran monárquicos o republicanos, en cuanto asumieron el control de la Diputación, trataron de implantar en estas escuelas sus respectivos modelos culturales y de nación, pero siempre desde una perspectiva española, con lo que planteamiento inicial vasquista se vio alterado.

\section{INICIO DEL PROYECTO MONÁRQUICO ESPAÑOLISTA Y EL DESPLIEGUE PRIMORRIVERISTA}

Tras las elecciones de 1921 los monárquicos, ahora al mando de la Diputación, suprimieron ese mismo año las facultades ejecutivas de la Junta de Instrucción Pública, que pasó a ser un órgano consultivo y administrativo, carente de autonomía, con lo que el inspector Eleizalde se vio imposibilitado para dar continuidad al proyecto vasquista original. Los monárquicos adaptaron el proyecto original de las Escuelas de Barriada, que perdieron muy pronto gran parte de su contenido inicial, y comenzaron a utilizarse para alfabetizar en castellano la Bizkaia rural y euskaldun. Pero, tanto con unos como con otros, la rigurosa formación católica se mantuvo.

Durante la dictadura de Primo de Rivera, muchas cosas cambiaron en las Escuelas de Barriada, puesto que el nuevo régimen puso en marcha un intenso proceso de nacionalización de masas a través de la educación y el ejército. Ramón López Martín ${ }^{23}$ y Alejandro Quiroga ${ }^{24}$ han investigado el proceso de nacionalización iniciado por Primo de Rivera en el ámbito educativo. Quiroga, además, menciona el caso de las escuelas rurales vizcaínas, ${ }^{25}$ pero merece la pena profundizar en los cambios que supuso para ellas el nuevo contexto político.

\footnotetext{
${ }^{23}$ Ramón López Martín, Ideología y educación en la dictadura de Primo de Rivera (Valencia: Universidad de Valencia, 1995).

${ }^{24}$ Alejandro Quiroga, «Maestros, espías y lentejas. Educación y Nacionalización de masas durante la Dictadura de Primo de Rivera», en Construir España. Nacionalismo español y procesos de nacionalización, ed. Javier Moreno (Madrid: Centro de Estudios Políticos y Constitucionales, 2007), 183-205; y Alejandro Quiroga, Haciendo españoles. La nacionalización de las masas en la Dictadura de Primo de Rivera (1923-1930) (Madrid: Centro de Estudios Políticos y Constitucionales, 2008).
}

${ }_{25}$ Quiroga, Haciendo españoles, 239-245. 
Para empezar las Escuelas de Barriada tuvieron que seguir el régimen general de enseñanza de las escuelas nacionales y, por lo tanto, aparte de las inspecciones de la Diputación, estas escuelas empezaron a ser visitadas también por inspectores nacionales. ${ }^{26}$ Sin embargo, el profesorado no pasó al Estado, sino que siguió en manos de la Diputación.

En el ámbito pedagógico se mantuvo en líneas generales el planteamiento inicial de la Escuela Nueva, tal y como ocurrió en el resto de escuelas públicas de España, ${ }^{27}$ pero los recursos didácticos disminuyeron. Todas las Escuelas de Barriada construidas antes de la Dictadura de Primo de Rivera tuvieron una caja de construcciones de Froebel, pero las escuelas posteriores, según los inventarios realizados por las maestras, no fueron abastecidas con este material, aunque según la lista oficial de 1924 de la Diputación (Material de enseñanza para cada escuela) se seguía mencionando como material básico. Los inventarios de la dictadura muestran unas escuelas con muchos libros de texto en castellano y de lectura - llegan los primeros Quijotes y demás libros de lectura - y mapas —incluso de Bizkaia-. Materiales, sobre todo los de texto, en los que se podía apoyar el profesorado menos experto en la pedagogía activa.

Por otro lado, la dictadura profundiza el proceso de castellanización de las Escuelas de Barriada, iniciado por la Diputación de la Liga Monárquica, ya que prohibió el uso del euskera en dichas Escuelas mediante la R.O. de 16 de octubre de $1925 .{ }^{28}$ Realmente esa política ya funcionaba en las Escuelas de Barriada anteriormente, puesto que a partir de 1924 ninguna escuela fue abastecida con libro alguno en euskera, ni siquiera con el catecismo. Aunque los textos no estuvieran en lengua vasca, y a pesar de la Real Orden, no creemos que en las escuelas se abandonara completamente el uso oral del euskera puesto que el alumnado era casi monolingüe, e instruirlo solo en castellano no hubiera tenido

\footnotetext{
${ }^{26}$ No sabemos si la inspección del Estado fue asidua. Tenemos pocas noticias de este tipo de inspecciones. Podemos confirmar la inspección de San Miguel de Dudea (Amorebieta-Etxano) en junio de 1925, que no parece que tuviera mayor repercusión. «Expediente de creación y gestión de la Escuela de Barriada de San Miguel de Dudea», caja 3, AHFB.

27 López, Ideología y educación, 150.

28 Arrien, Educación y escuelas de barriada, 146.
} 
sentido; además, parte del profesorado era euskaldun y el propio reglamento oficial de 1923 de las Escuelas de Barriada permitía que el profesorado lo utilizara en clase:

Art. 59. Respondiendo a la distribución de las Escuelas de barriada en las categorías a) y b), las enseñanzas de ambas se dará en lengua castellana, sirviéndose el Maestro de la lengua vasca como medio de enseñanza en aquellos alumnos que desconozcan el castellano. ${ }^{29}$

Aun así, el contexto general era contrario al euskera, y generaba inseguridad entre el profesorado. En 1924 la maestra de Berreño (Munitibar) solicitaba por carta a la Junta de Instrucción que le confirmase cual debía ser la lengua de instrucción del catecismo, a pesar de que el reglamento indicaba que sería la vasca:

El artículo 59 del Reglamento de Escuelas de barriada dice, que, las enseñanzas se daran en lengua castellana; hasta ahora, aunque se hacía así, se excluía a la Doctrina Cristiana la cual se daba en lengua vasca. Le agradeceré se sirva indicarme si hay que enseñar la Doctrina en vascuence o en castellano. ${ }^{30}$

En esta misma línea vamos a presentar el caso de Indusi, en el barrio de Oba (Dima) en el que en 1927, los resultados académicos del alumnado eran tan bajos, que la Diputación decidió mandar a una maestra para reorientar la instrucción de esta escuela. El encargo recayó sobre la maestra nacionalista Purificación Mandiola. Según su informe «las lecturas y los ejercicios deben] ser la base de la formación del lenguaje que tanto esfuerzo exige al maestro de barriada, que tiene que poner los cimientos del idioma oficial». ${ }^{31}$ Lo llamativo de esta cita es que la maestra hace referencia a la lengua española como lengua oficial,

\footnotetext{
29 «Reglamento de Escuelas de Barriada» (1923). El reglamento de 1926 tuvo una redacción más detallada de este artículo de la normativa: «Art. 57. Respondiendo a la distribución de las Escuelas de barriada en las categorías "A" y "B", según se establece en el artículo 26, la enseñanza en ambas se dará, precisamente, en lengua castellana; pero en las de la categoría "A" el maestro viene obligado a servirse de la lengua vasca como medio o vehículo de enseñanza, con relación a cuantos alumnos desconozcan el castellano, teniendo muy presente que su misión es precisamente la de enseñárselo», Reglamento de Escuelas de Barriada, 1926.

30 «Expediente de creación y gestión de la Escuela de Barriada de Berreño», caja 3, AHFB.

31 «Expediente de creación y gestión de la Escuela de Barriada de Indusi», caja 9, AHFB.
} 
cuando en España no tenía aún esa categoría jurídica. ${ }^{32}$ Más adelante la maestra daba cuenta a la Junta de Instrucción Pública de una de las medidas que había tomado para reforzar el aprendizaje del español entre el alumnado: "en la escuela de Indusi, quedó impuesta la obligación, (en los grados mayor y mediano) de hablar en castellano, para toda petición y comunicación entre los alumnos de dichos grados y su maestra».33 Se trata de una medida un tanto excepcional "justificada" por la situación.

En lo que a religión se refiere, el catolicismo que impulsó Primo de Rivera a través de la instrucción no supuso un cambio sustancial, ya que en estas escuelas, desde su diseño original, la religión ocupaba un lugar destacado. Aunque lo cierto es que con Primo de Rivera los símbolos religiosos dentro del aula cambiaron. Hasta 1924 cada Escuela de Barriada disponía de un cuadro donde aparecía Jesucristo entre niños ( DDejad que los niños se acerquen a mí»), una imagen más cercana y amigable, que el crucifijo que se impuso a partir de ese año.

La novedad no vino de la mano de lo católico, sino del proyecto de nacionalización pretendido. El proyecto de Primo de Rivera buscaba crear patriotas, que se sintieran ciudadanos de la nación española y para lograrlo utilizó la instrucción pública, además del ejército. ${ }^{34}$ Todo ello se conseguía, en el caso de las escuelas, a través de una política lingüística castellanizadora, de la enseñanza de la historia española, de la celebración de conmemoraciones relacionadas con el régimen y la patria, y de la exaltación de símbolos patrióticos, como la bandera española, que debía ser izada y que hasta entonces no se conocía en estas escuelas rurales, pero que consta a partir de la dictadura. A continuación, vamos a tratar de explicar cómo se vivió en estas escuelas este breve pero intenso periodo político, poniendo especial atención en el alumnado y profesorado, ya que ambos mostraron diversas resistencias y/o complicidades en las Escuelas de Barriada.

\footnotetext{
32 Daniel Escribano, «La introducció del concepte de llengua oficial a l’ordenament jurídic espanyol (1902-1931)», Treballs de Sociolingüística catalana 25 (2015): 213-229.

33 «Expediente de creación y gestión de la Escuela de Barriada de Indusi», caja 9, AHFB.

34 Quiroga, «Maestros, espías y lentejas», 183.
} 


\section{PREFERENCIAS DE LAS FAMILIAS}

Las familias vizcaínas en general preferían mandar a sus hijos e hijas a las Escuelas de Barriada, que a las nacionales. Por ello, las de barriada estuvieron en muchos casos abarrotadas. Esto generaba muchos conflictos dentro de la propia escuela (las maestras tenían que llevar rigurosamente la matrícula, y no exceder el cupo), y también entre la Junta local, que gestionaba la escuela, y la de la Diputación. En una Escuelas de Barriada típica, unitaria, la matrícula era de 48, pero esta cifra se superaba muchas veces. Si alrededor del barrio había una escuela nacional, el inspector examinaba la procedencia del alumnado, para mandarlos a la misma. Si no había ninguna escuela nacional, a los más pequeños se les sacaba de la Escuela de Barriada para que pudieran entrar los mayores, y se les aceptaba el curso siguiente. Para la Diputación era imprescindible limitar la matrícula por motivos higiénicos y para que los objetivos académicos perseguidos fueran alcanzados por el alumnado. En este sentido, las juntas locales y las familias constructoras presionaban para que todo el alumnado del barrio fuera aceptado, ya fuera un poco de más acá o de más allá. Los motivos quizá no eran tanto académicos, que también, ya que la metodología y la didáctica eran mucho más modernas en las de barriada, sino también porque la de barriada era la escuela de la comunidad, del barrio, y en el País Vasco, el barrio (auzoa), es una unidad de pertenencia comunitaria e identitaria importante. Es más, muchas de estas escuelas fueron construidas por las familias de estos barrios, como uno de tantos trabajos que se realizaban a favor de la comunidad en régimen de auzolan.

A veces los niños eran expulsados de las Escuelas de Barriada por las familias constructoras, porque sus padres no pagaban la cuota mensual. Si bien la enseñanza de dichas Escuelas era pública y gratuita, las familias constructoras tenían derecho a pedir una cuota para el mantenimiento del edificio escolar. La cuota máxima estaba estipulada en 2 pesetas. Aun así en más de una ocasión surgieron problemas serios. Por ejemplo, en la escuela San Lorenzo (Zaldibar) en 1931 aparece este problema. El padre del niño Imanol Casalis de 8 años escribió al inspector informándole de que habían echado de la escuela a su hijo porque no había pagado la cuota impuesta por las familias constructoras. Según el padre «esta escuela frecuentan algunos alumnos de la barriada de Olarreaga y que pertenesen (sic) a Guipuzcoa, y yo soy de Ermua durante 
30 años y en este pueblo tenemos el maestro Nacional tan malo que no se le puede mandar ningún niño a sus manos». ${ }^{35}$ Este caso es interesante, porque más allá del problema de las cuotas, muestra detalles reveladores sobre el contexto de las Escuelas de Barriada: niños de un barrio cercano pero de la provincia de Gipuzkoa asistían a esta escuela, el niño expulsado se llamaba Imanol, nombre perteneciente a la onomástica sabiniana, ${ }^{36}$ vivía en Ermua (villa de Bizkaia), en el centro del pueblo, en la zona de la plaza, y que aunque le correspondía asistir a la escuela nacional, Imanol fue matriculado en la escuela del barrio a la que iban todos los hijos de los agricultores. Una razón quizá fuera que el maestro nacional de Ermua era realmente «malo» tal y como denunciaba el padre, pero cabe la posibilidad de que siendo el padre nacionalista, euskaldun poco versado en la lengua de Cervantes (la carta anterior es elocuente), prefiriera mandar a su hijo a una escuela en la que no se perseguía el uso del euskera. No fue el único caso en esta escuela de San Lorenzo. Andoni Mancholas con 6 años de edad y residente en Ermua, y por lo tanto tampoco del barrio, solicitó asimismo su ingreso en la de San Lorenzo.

En este contexto de posible «fuga» de matrícula hacia las escuelas rurales, las nacionales se pusieron a la defensiva, por lo que el inspector Pedro Zufía en 1926 tuvo que elaborar un informe por cada municipio en el que hubiera una escuela nacional y una o varias de barriada. Bajo ningún concepto las Escuelas de Barriada podían quitar matrículas a las nacionales. Todos los informes de Zufía que hemos consultado analizan la situación particular de cada pueblo y siempre justifican la necesidad de mantener abierta la de barriada, debido principalmente al elevado número de niños matriculados en ellas.

En definitiva, las Escuelas de Barriada no podían alterar el statu quo de las nacionales, pero se aceptaba que fueran complementarias a ellas. La Junta Provincial tenía que velar por «evitar rozamiento entre los

\footnotetext{
35 «Expediente de creación y gestión de la Escuela de Barriada de San Lorenzo», caja 25, AHFB.

36 Gracias a este problema en la matricula, la Diputación solicitó la lista de los niños que acudían a la escuela, en la que aparecen otros 4 niños, de un total de 50, con nombre sabiniano: Miren Lizaso, Iñaki Pildain, Josu Aguirre, y Joseba Idigoras. El uso de nombres en euskera en Bizkaia antes de la Guerra Civil rondaba el 10\% y en el caso de San Lorenzo, se cumple con ese promedio, ver Mikel Gorrotxategi, «Errepublika garaiko izenak eta 1939ko dekretua», Fontes Linguae Vasconum 102 (2006): 321-352.
} 
centros nacionales y los de barriada». ${ }^{37}$ Sin embargo, tal y como hemos apuntado anteriormente, la práctica era diferente. Las Escuelas de Barriada solían tener la matrícula completa, y el excedente muchas veces tenía que optar, muy a su pesar, por asistir a la nacional, tal y como recoge el acta de septiembre de la Junta local de enseñanza de Astelarra (Muxika) que protestaba por la reducción por parte de la Provincial del número de matrículas: «[...] d) que hay otros niños de caseríos más cercanos a la línea divisoria (y por tanto a esta escuela) que el susodicho Arteta, y que, por consiguiente asisten a las Escuelas Nacionales, a pesar de haber solicitado el ingreso en esta de barriada». ${ }^{38}$ En casos de excedente de matrícula, se miraba mucho la localización de la vivienda y no se dudaba en denunciar cualquier matrícula intrusa, para evitar que algún niño o niña del barrio tuviera que marcharse a una escuela nacional. Así pues, las Escuelas de Barriada eran la primera opción de las familias que tenían niños y niñas en periodo escolar.

Cabe pensar que las de barriada pudieron ser una primera opción, no solo por lo motivos apuntados (higiénicos, educativos y comunitarios), sino también porque en ellas se podía hablar en euskera no sólo con los compañeros y compañeras, sino incluso con la profesora sin sufrir una sanción lingüística como la que se ejercía en las escuelas nacionales. Una familia podía llegar comunicarse con el maestro o maestra de su hijo sin dificultades lingüísticas y sin sentirse en inferioridad cultural. Aunque en las escuelas de barriada el objetivo final era el aprendizaje del español, el régimen pedagógico y lingüístico era más abierto y/o amable para las familias euskaldunes. En definitiva, estos niños de los barrios, en las nacionales, tenían menos opciones de éxito académico, no sólo porque no conocían la lengua de instrucción sino también porque el mensaje implícito de inferioridad cultural resultaba bastante claro.

\section{EL PROFESORADO DE LAS ESCUELAS DE BARRIADA}

La provisión de profesorado para las Escuelas de Barriada se realizó mediante concurso público. La Diputación de Bizkaia convocó casi

\footnotetext{
37 «Acta de 28.09.1926 de la Junta local de enseñanza. Expediente de creación y gestión de la Escuela de Barriada de Astelarra», caja 20, AHFB.

38 «Expediente de creación y gestión de la Escuela de Barriada de Astelarra», caja 20, AHFB.
} 
anualmente oposiciones, 13 en total antes de 1936. Se confeccionaron 4 listas de profesores, dos para cada género, y dentro de cada una de ellas se diferenciaban las destinadas a escuelas tipo «A» 0 «B». Según el reglamento, los requisitos que tenían que cumplir las candidatas y candidatos para poder participar en la oposición eran tres: a) poseer el título oficial; b) presentar un certificado médico de capacidad física y sanitaria, y c) edad mínima de 18 años para las maestras, y 20 años para los maestros. Además, para las escuelas de categoría «A», debían superar un examen de euskera. Según la documentación consultada, al menos 215 maestras y 14 maestros trabajaron en algún momento en estas escuelas. El 80\% del profesorado no solo era euskaldun sino que estaba capacitado y acreditado para la enseñanza en lengua vasca.

Este gran cuerpo de maestras y maestros es prácticamente desconocido. La excepción la constituyen aquellas maestras que tuvieron una activa militancia política nacionalista, sobre todo aquellas que participaron en la agrupación Emakume Abertzale Batza (Asociación de Mujeres Patriotas, en adelante, EAB). Esta agrupación creada en 1922 tenía como objetivo difundir la doctrina nacionalista vasca, desarrollar actividades culturales, sociales y benéficas. La Dictadura de Primo de Rivera ilegalizó esta y otras asociaciones y en 1933, ya en el contexto de la República, resurgió EAB. ${ }^{39}$

Las maestras de barriada que, según la bibliografía consultada, pertenecieron a EAB fueron: Encarnación Velasco, Sorne Unzueta, Josefa Ines Aranzadi, Carmen Egia, Purificación Mandiola, Consuelo Gallastegi, Julene Azpeitia ${ }^{40}$ y Petra Gandarias. Por lo tanto, declaradamente nacionalistas fueron ocho maestras. A primera vista podría parecer que no eran tantas, pero ejercieron un notable liderazgo dentro del cuerpo docente. Resulta significativo que en la primera oposición de la Diputación para las Escuelas de Barriada fuesen dos de estas mujeres las que ocuparon los primeros dos puestos: Azpeitia y Gandarias. Azpeitia además fue nombrada en la oposición de 1920 directora del cuerpo femenino. ${ }^{41}$ Cargo que aceptó, aunque pronto dimitiera por motivos personales.

\footnotetext{
39 Mercedes Ugalde, Mujeres y nacionalismo vasco. Génesis y desarrollo de Emakume Abertzale Batza. 1906-1936 (Leioa: UPV/EHU, 1993).

40 Garmendia, Zabaleta y Murua, «Alfabetización en euskara», 220.

${ }^{41}$ Según el informe del inspector Luis Eleizalde: «En los ejercicios de eliminación recientemente practicados entre las maestras aspirantes a escuelas de barriada de las categorías "A" y "A-B", pudo
} 
Este pequeño grupo de maestras nacionalistas ha sido investigado por su labor política y trabajos intelectuales, y no tanto por su labor docente. La única maestra que ha merecido una atención mayor ha sido Julene Azpeitia, sobre la que también existen investigaciones sobre su labor educativa. ${ }^{42}$ Poco sabemos de aquellas maestras que no militaron en agrupaciones políticas, pero por diversos indicios cabe suponer que muchas de ellas eran simpatizantes o cercanas al nacionalismo vasco. Resulta revelador que tras la Guerra Civil, según Ostolaza, un total de 70 maestras y maestros de las Escuelas de Barriada trataron de reincorporarse a sus puestos de trabajo y se sometieron a los expedientes de depuración: solo 5 fueron confirmados en sus cargos, mientras que los 65 restantes sufrieron diversas sanciones. Sobre el resto de docentes de las Escuelas de Barriada sobre los que no hay informes «debemos suponer que ni siquiera llegaron a presentar la solicitud de reingreso, seguramente por la dificultad de conseguir informes favorables, de modo que fueron automáticamente expulsados del servicio».43 Sería interesante rescatarlos del anonimato y poder investigar su recorrido vital y labor educativa, para conocer lo que realmente pasó en las aulas de las Escuelas de Barriada, más allá de lo que el horizonte político-educativo de la Diputación marcaba.

El cuerpo de maestras era demasiado amplio para abordarlo en este breve trabajo, por lo que hemos seleccionado un caso que puede servir de ejemplo de lo que vivieron y experimentaron muchas de ellas: el de María Learreta Pertika. Esta maestra nacida en Ajangiz (Bizkaia) en

V. S. apreciar las verdaderamente relevantes condiciones y capacidad de la aspirante Dña. Josefa Juliana de Azpeitia. Los ejercicios practicados por esta Sra., su clara y perfecta visión del problema pedagógico general y del especial cuya solución persigue la institución de escuelas de barriada, los conocimientos prácticos e interesantes observaciones acerca de la moderna escuela y las provechosas orientaciones que ante V. S. tuvo el acierto de exponer, colocaron a esta aspirante en un plano superior relativamente al del grupo de las restantes aspirantes, algunas de ellas muy brillantes, sin embargo. En estas condiciones, [...] Azpeitia no está indicada para ocupar una sencilla plaza de maestra en escuelas de barriada. Dicha Sra. puede prestar utilísimos servicios a la Ponencia y a la Junta de Instrucción Pública encargándose de la orientación, dirección y en ciertos casos formación del profesorado femenino». «Expediente personal de la maestra Julene Azpeitia», AHFB.

42 Gregorio Arrien y J. Javier Granja (eds.), Julene Azpeitia ehun urte mugan (1888-1988) (Bilbao: Zumaiako Udala, 1998); Idoia Fernández Fernández, «Género, educación activa, lengua y nación en el País Vasco. Julene Azpeitia (1888-1980), exponente de una educación vasca en ciernes», Historia de la educación 31 (2012): 275-297.

${ }_{43}$ Maitane Ostolaza, El garrote de la depuración. Maestros vascos en la Guerra Civil y primer franquismo (1936-1945) (San Sebastián: Ibaeta Pedagogía, 1996), 141. 
1892, quedó tercera de entre las 49 candidatas, en la primera oposición de la Diputación para las Escuelas de Barriada. Learreta; católica y simpatizante nacionalista, estuvo afiliada a la Agrupación de Maestros Vascos (Eusko irakasle Batza/Bazkuna), una asociación adscrita al sindicato nacionalista ELA/SOV que se creó en 1931. ${ }^{44}$ En plena Guerra Civil, el 17 de mayo de 1937, varias maestras de barriada nombradas por el Gobierno Vasco, viajaron en la expedición de niños y niñas que salieron a Inglaterra, para ejercer como maestras auxiliares de las colonias escolares que se pusieron en marcha en ese país. Learreta estuvo en Inglaterra hasta que las colonias prácticamente se cerraron. En diciembre de 1939 decidió regresar cruzando la frontera desde el lado francés, por Hondarribia y se presentó ante las autoridades que la dejaron libre sin cargos. Tras su vuelta, en varias ocasiones solicitó su reingreso en el cuerpo de maestras, para lo que presentó numerosos documentos acreditativos de su intachable conducta moral y religiosa (firmados por los párrocos que la conocieron), y de su celo profesional como maestra (del que hablaban tanto los padres de los niños con los que estuvo antes de la guerra, así como los inspectores). Pero no fue readmitida en un primer momento. Entre 1939 y 1948 no sabemos exactamente a qué se dedicó. Residía en Bilbao y tenía una estrecha relación con la parroquia de la Basílica de Santiago, donde fue secretaria del director de la catequesis. Aunque nunca participara en actividades políticas, como lo hicieron otras maestras ya mencionadas, debido a su colaboración con las colonias y su afiliación sindical sufrió las consecuencias de un expediente de depuración. Al final en 1948 consiguió que el juez del Juzgado Superior de Revisiones, tras volver a revisar su expediente, dejara sin efecto las órdenes anteriores que la separaban del servicio y la readmitiera como maestra, pero con una sanción, ya que por «su ideario pudiera ser peligrosa en la educación de la infancia». La sanción estipulaba que en 5 años no podría impartir docencia en escuelas de las provincias vascongadas y la inhabilitaba para cargos directivos y de confianza.

\footnotetext{
${ }^{44}$ Según la bibliografía consultada, esta agrupación tenía más de 150 maestros y maestras afiliadas. En el caso de las de barriada, sabemos que estos profesores pertenecieron a la misma: Julene Azpeitia, Carmen Egia, Julia Egia, Miren Egia, Consuelo Gallastegi, Julian Irigoien, Maria Learreta, Purificación Mandiola, Delfín Puelles y Primitiva Unzueta. Es muy probable que participaran más profesores de barriada en esta asociación, pero no hemos podido consultar la lista completa de afiliados que se encuentra en el Archivo de Salamanca. Ver: Arrien, Educación y escuelas de barriada, 188; Itziar Rekalde, Escuela, educación e infancia durante la Guerra Civil en Euskadi (Salamanca: Universidad de Salamanca, 2001), 428.
} 


\section{COMPLICIDADES Y POSIBLES RESISTENCIAS DEL PROFESORADO}

Todas las maestras mencionadas hasta ahora, nacionalistas o simpatizantes, siguieron las orientaciones de la Diputación y las órdenes del Gobierno de Primo de Rivera, sin aparente desobediencia. Por el contrario, durante la II República, en este mismo grupo de maestras se observa cierta contestación a las directivas superiores. Por ejemplo, Julene Azpeitia opuso resistencia física ante las personas que por orden del gobierno debían quitar el crucifijo del aula. ${ }^{45}$ Un símbolo religioso que no existía en la fase vasquista y que llegó a las escuelas con Primo de Rivera.

Otros dos símbolos importantes de carácter político, que se impusieron en todas las escuelas de España durante la dictadura primorriverista, fueron el retrato del rey y la bandera española. Los tres símbolos llegaron en 1924 a las Escuelas de Barriada, aunque a veces la bandera llegó un año más tarde que el crucifijo y el retrato real, por ejemplo, en Berreño (Munitibar) o en Baldatika (Forua). En realidad, todas las escuelas deberían haber tenido una bandera española desde el principio de la dictadura, ya que el reglamento de 1923 recogía en el artículo 67 que: «Durante las horas de clase ondeará la enseña nacional en el frontis y lugar preferente del edificio escolar. Es obligación del Maestro respectivo dar cumplimiento exacto a este precepto». Como se puede apreciar en el reglamento, el cuerpo de maestros aparece como pieza clave de propaganda política. En el caso de las Escuelas de Barriada, atisbamos cierta laxitud en la aplicación de esta norma, que no sabemos muy bien si proviene de los maestros, de la Diputación, o bien del contexto en general. En este sentido recogemos el breve relato de la maestra Francisca Garbizu de Arbaiza (Orozko) recuperado en un informe de asistencia:

Hace tiempo que en la Escuela no se coloca la bandera porque el viento se llevó la cuerda que la sujetaba y no la colocan. De todos modos en los día de viento es imposible colocarla porque al chocar con la fachada se destroza y los vecinos dicen que el asta no puede colocarse en la plazoleta que hay delante de la Escuela porque el terreno no les pertenece y el dueño no le permite hacerlo. ${ }^{46}$

\footnotetext{
${ }^{45}$ Hecho mencionado en la solicitud de reincorporación al cuerpo de maestras del 03.07.1947 redactado por J. Azpeitia. «Expediente personal de la maestra Julene Azpeitia», AHFB.

${ }^{46}$ Nota de F. Garbizu en el informe de asistencia de 25.02.1927. «Expediente de asistencia de la Escuela de Barriada de Arbaiza», caja 1983, AHFB.
} 
Esto no obsta para que en otras Escuelas de Barriada se izara la bandera española con regularidad. El hecho mismo de que la maestra de Arbaiza se viera obligada a dar explicaciones sobre este asunto, muestra que existía una inspección para hacer efectivos los preceptos legales referentes a los símbolos nacionales.

En cuanto a las celebraciones, una de las ceremonias patrióticas que instauró la Dictadura de Primo de Rivera, fue la Fiesta del Árbol. En las Escuelas de Barriada las maestras debían informar a la Diputación sobre el día que iban a dedicar a esta celebración, para que pudieran acudir junto con los representantes del ayuntamiento y el cura, miembros de la Diputación. La maestra R. Belzunegi de Asterrika (Berriatua) consideraba que era una simpática y educadora celebración. ${ }^{47}$ Pero quizá el profesorado de las escuelas de Erletxeta y Bengoetxe pertenecientes al municipio de Galdakao no pensaba igual, ya que no colaboraron con la organización del evento. El alcalde informó en estos términos sobre las cuatro maestras (M. L. Mujika y S. Campos de Erletxeta, y M. A. Gorriño y S. Barrenetxea de Bengoetxe) y el maestro (J. Sorazu de Bengoetxe) implicados:

Por último, no puedo menos de hacer constar, la impresión desagradable que ha podido causar la falta de asistencia del Profesorado de las escuelas de barriada, que a pesar de [ilegible] invitado repetidas veces por la Alcaldía, no ha concurrido a las reuniones convocadas para la organización de la FIESTA DEL ARBOL, que por disposición Superior se hace preciso celebrar. ${ }^{48}$

La respuesta de la Junta de Instrucción Pública de la Diputación fue contundente: si no participaban en la celebración iban a ser suspendidos de empleo y sueldo (acta del 24.03.1926). No podemos determinar si las razones para la desobediencia son propiamente políticas o también concurría una protesta laboral mencionada en el informe, porque el profesorado de la escuela nacional recibía una gratificación por parte del ayuntamiento que no percibía el de barriada.

\footnotetext{
47 «Expediente de creación y gestión de la Escuela de Barriada de Asterrika», caja 5, AHFB.

48 Carta del 22.03.1926 de León Azua a la Junta de Instrucción Pública de la diputación. «Expediente de creación y gestión de la Escuela de Barriada de Bengoetxe», caja 11, AHFB.
} 
Un año más tarde, María Learreta, con motivo de las Bodas de Plata de la nación de Alfonso XIII, que conmemoraban el XXV aniversario de su subida al trono, dedicó una mañana a explicar los hechos más sobresalientes del rey «sirviéndonos de revistas ilustradas, a falta de proyecciones para hacer más interesante la explicación».49

Este, y otros casos, muestran que en general el profesorado de las Escuelas de Barriada colaboró con las celebraciones y demás ceremonias del régimen tanto con las de carácter político como religioso. Una festividad católica ligada a la dictadura de Primo de Rivera fue la entronización del Sagrado Corazón de Jesú ${ }^{50}$ que también se celebró en algunas Escuelas de Barriada. ${ }^{51}$

Las maestras de barriada eran creyentes e, incluso fervientes católicas. Alguna, como es el caso de Petra Gandarias, que ocupó el segundo lugar en la primera oposición de 1920 y que fue vocal de la primera junta directiva de la agrupación EAB, en 1924 ingresó como novicia en la congregación Esclavas del Sagrado Corazón, y en 1932 realizó su profesión permanente. No es el único caso, pero sí el más conocido.

\section{CONCLUSIONES Y FUTURAS LÍNEAS DE INVESTIGACIÓN}

El diseño inicial de las Escuelas de Barriada, tenía la clara intención de crear en el medio rural una red de escuelas vascas, respetuosa con la pluralidad lingüística de Bizkaia y en sintonía con las ideas pedagógicas europeas, con el objetivo de convertir un país económicamente próspero en un país sin analfabetismo y con unas cotas más altas de cultura. La materialización de la propuesta no llegó muy lejos. Al año de su puesta en marcha, la nueva Diputación monárquica comenzó a constreñir el proyecto. La lengua vasca quedó relegada al uso oral en el

\footnotetext{
49 Parte quincenal de asistencia del 21.05.1927. «Expediente de asistencia de la Escuela de Barriada de Arkotxa», caja 1972, AHFB.

${ }^{50}$ Luis Cano, «La devoción al Sagrado Corazón y a Cristo Rey en España y su recepción por los metropolitanos españoles (1923-1931)» (Tesis doctoral, Pontificia Universitas Sanctæ Crucis Facultas Theologiæ, 2007), 324-333.

51 Por ejemplo, las maestras M. Mihura, de San Miguel de Dudea, en 1926, y al año siguiente P. Gamecho, de Barinaga, organizaron sendas celebraciones de entronización del Sagrado Corazón de Jesús. «Expediente de creación y gestión de las Escuelas de Barriada de San Miguel», caja 3 y «Expediente de creación y gestión de las Escuelas de Barriada de Barinaga», caja 19, AHFB.
} 
aula y la dictadura de Primo de Rivera acentuó aún más la orientación españolista iniciada por la Diputación monárquica. Parece, pues, que se puede hablar del fracaso del proyecto vasquista inicial de las escuelas rurales de Bizkaia. Un fracaso inducido desde las instancias del poder. Pero quizá fuera mejor hablar de un fracaso relativo. Porque, aunque el diseño inicial se transformó al compás del devenir político de la provincia, las bases pedagógicas y unos mínimos lingüísticos se mantuvieron. Esto proporcionó un entorno escolar y cultural más apropiado para los niños y niñas euskaldunes de Bizkaia. Si se hubieran diseñado estas escuelas en plena dictadura para atender la instrucción de la población, seguramente no se hubiera aceptado ninguna presencia de la lengua vasca en el aula.

Por otro lado, nos interesa subrayar la escasa resistencia documentada por el profesorado, aunque una parte destacada de la misma fuese en principio nacionalista o simpatizante, frente a las exigencias dictadas por la Diputación en el periodo primorriverista. Quizá fuese por la juventud de las maestras, puesto que las que ingresaron en las Escuelas de Barriada eran jóvenes de 20-21 años, que acababan de conseguir el título de maestras, (excepto en la primera oposición, a la que concursaron maestras de entre 28-30 años como J. Azpeitia, M. Learreta...). Además de jóvenes, eran solteras y católicas. Todas ellas contaban con conductas morales intachables, según las fuentes principales de control social, la iglesia y la policía. Por lo tanto, no estaban acostumbradas a la vida pública o política, sino a obedecer y a no llamar la atención. Creemos que dentro de este grupo difícilmente vamos a encontrar actos de desobediencia radical o desorden. Según hemos mostrado, algunas maestras, quizá por razones políticas, quizá no, dieron muestra de pequeñas desobediencias y laxitudes en el periodo de la dictadura de Primo de Rivera. Pero sobre todo colaboraron, con mayor o menor gana, en la transmisión de los principales valores políticos, religiosos y lingüísticos del régimen. Así, por ejemplo, la militante nacionalista y maestra Purificación Mandiola tenía clara la necesidad de enseñar la lengua española, que incluso calificaba de oficial, en las Escuelas de Barriada. El hecho de que tanto el nacionalismo vasco de la época como la dictadura de Primo de Rivera se sustentaran en gran medida sobre la religión católica facilitó probablemente esta colaboración y escasa resistencia. También es posible que la formación recibida en las Escuelas Normales, con un claro sesgo cultural español, ayudara a la aceptación de los modelos hegemónicos. 
El periodo de la II República ha quedado fuera del análisis de este trabajo. Algún dato suelto que hemos recogido, como el caso de una resistencia de tinte confesional por parte de una maestra nacionalista, apunta a que también sería interesante investigar dicho periodo. La Guerra Civil y el franquismo marcan otra época radicalmente nueva. Con la entrada de las tropas franquistas y la toma de Bizkaia en 1937, las Escuelas de Barriada pasaron a ser administradas directamente por el Estado $^{52}$, y en agosto de ese mismo año comenzó el proceso de depuración del cuerpo docente ${ }^{53}$. Estas cuestiones y el devenir de las maestras y maestros tras la Guerra Civil merecen nuevas investigaciones.

\section{Nota sobre la autora}

Karmele Artetxe Sánchez es profesora del Departamento de Teoría e Historia de la Educación en la Facultad de Educación de Bilbao (UPV/ EHU) desde 2012. Se licenció en Historia en 1999 y obtuvo el doctorado en la misma área (2010). En su tesis investigó el proceso de implantación de la educación superior en el País Vasco a lo largo del siglo XX y su relación con la modernización de la lengua vasca. Posteriormente orientó sus trabajos hacia etapas de enseñanza no universitaria (como muestran, entre otros, su estudio sobre el proyecto vizcaíno Ikastetxea de 1896 de Resurrección María Azkue). En sus trabajos se cruzan la historia cultural y social del País Vasco con la educación. Su ensayo Einstein Euzkadin. Gerraurreko zientzia eta goi mailako kultura euskaraz. [=Einstein en Euzkadi. Ciencia y cultura en lengua vasca antes de la Guerra Civil] fue seleccionado para optar al Premio Euskadi de Ensayo del Gobierno Vasco en el 2014. Por otra parte, y como docente en el Grado en Educación Social, en la actualidad también investiga el origen y desarrollo de proyectos y entidades relacionadas con la historia de la Educación Social, como el Programa Municipal de Educación de Calle (PEC) de Vitoria-Gasteiz o la Cooperativa de Iniciativa Social Agintzari.

\footnotetext{
52 Gregorio Arrien, «Educación y escuelas de barriada de Vizcaya, 1937-1939 (su traspaso al estado y deterioro de la enseñanza)», Revista Internacional de Estudios Vascos 31, no. 3 (1986): 629-640.

53 Sobre este proceso de depuración destacamos el trabajo más completo hasta la fecha de Aritz Ipiña, Represión y terror franquista en la Diputación de Bizkaia: fusilamientos y depuración (19361976), 190-217.
} 


\section{REFERENCIAS}

Arrien, Gregorio. «Educación y escuelas de barriada de Vizcaya, 1937-1939 (su traspaso al estado y deterioro de la enseñanza)». Revista Internacional de Estudios Vascos 31, no. 3 (1986): 629-640. http://hedatuz.euskomedia. org/1674/1/3106290640.pdf

Arrien, Gregorio. Educación y escuelas de barriada de Bizkaia. (Escuela y Autonomía. 1898-1936). Bilbao: Diputación Foral de Bizkaia, 1987.

Arrien, Gregorio y J. Javier Granja (eds.). Julene Azpeitia ehun urte mugan (1888-1988). Bilbao: Zumaiako Udala, 1998.

Arrien, Gregorio, Iñaki Pereda y Gorka Pérez de la Peña. Escuelas de barriada de Bizkaia, construyendo un paisaje educativo (1919-1937). Bilbao: Diputación Foral de Bizkaia, 2015.

Bilbao, Begoña, Gurutze Ezkurdia, Karmele Perez y Josu Chueca (comps.). Emakumeak hitza eta bizitza. Leioa: UPV/EHU, 2012.

Cano, Luis. «La devoción al Sagrado Corazón y a Cristo Rey en España y su recepción por los metropolitanos españoles (1923-1931)». PhD diss., Pontificia Universitas Sanctæ Crucis Facultas Theologiæ, 2007. https://www.isje. org/cano/LuisCanoMedina-SagradoCorazonyCristoRey.pdf

Dávila, Paulí e Iñaki Zabaleta. «La política educativa de las diputaciones vascas: entre proyectos y subvenciones». En Las politicas educativas en el País Vasco durante el siglo XX, coordinado por Pauli Dávila, 143-190. Madrid: Biblioteca Nueva, 2004.

Dávila, Paulí. La política educativa y la enseñanza pública en el País Vasco (18601930). Donostia: UPV/EHU, 1995.

Delgado, Ander. La otra Bizkaia. Politica en un entorno rural durante la restauración (1890-1923). Bilbao: UPV/EHU, 2008.

Escribano, Daniel. «La introducció del concepte de llengua oficial a l'ordenament jurídic espanyol (1902-1931)». Treballs de Sociolingüística catalana 25 (2015): 213-229. http://dx.doi.org/10.2436/20.2504.01.100

Fernández Fernández, Idoia. «Género, educación activa, lengua y nación en el País Vasco. Julene Azpeitia (1888-1980), exponente de una educación vasca en ciernes». Historia de la educación: Revista interuniversitaria 31 (2012): 275-297.

Garmendia, Joxe, Iñaki Zabaleta e Hilario Murua. «Alfabetización en euskara en las escuelas rurales del País Vasco (1900-1939)». Historia y Memoria de la Educación 7 (2018): 191-233. http://dx.doi.org/10.5944/hme.7.2018.18508

Gorrotxategi, Mikel. «Errepublika garaiko izenak eta 1939ko dekretua». Fontes Linguae Vasconum 102 (2006): 321-352.

Ipiña, Aritz. Represión y terror franquista en la Diputación de Bizkaia: fusilamientos y depuración (1936-1976). Bilbao: Pamiela, 2017. 
Kintana, Jurgi y Karmele Artetxe. «Ikastetxea 1896: un proyecto de colegio euskérico dirigido a la burguesía de Bilbao». Foro de Educación 25 (2018): 4968. http://dx.doi.org/10.14516/fde.675

Kintana, Jurgi. Intelektuala nazioa eraikitzen. R. M. Azkueren pentsaera eta obra. Bilbao: Euskaltzaindia: Real Academia de la Lengua Vasca, 2008.

López Martín, Ramón. Ideología y educación en la dictadura de Primo de Rivera. Valencia: Universidad de Valencia, 1995.

López Martín, Ramón. «La construcción y creación de escuelas en la España del primer tercio del siglo XX». Historia de la Educación 16 (1997): 65-90.

Ostolaza, Maitane. El garrote de la depuración. Maestros vascos en la Guerra Civil y primer franquismo (1936-1945). San Sebastián: Ibaeta Pedagogía, 1996. Paliza, Maite. El proyecto de las Escuelas de Barriada y su desarrollo (1919-1938). Una epopeya de la Historia de la Educación en Bizkaia. Bilbao: Gobierno Vasco, 2015.

Quiroga, Alejandro. «Maestros, espías y lentejas. Educación y Nacionalización de masas durante la Dictadura de Primo de Rivera». En Construir España. Nacionalismo español y procesos de nacionalización, editado por Javier Moreno, 183-205. Madrid: Centro de Estudios Políticos y Constitucionales, 2007.

Quiroga, Alejandro. Haciendo españoles. La nacionalización de las masas en la Dictadura de Primo de Rivera (1923-1930). Madrid: Centro de Estudios Políticos y Constitucionales, 2008.

Rekalde, Itziar. Escuela, educación e infancia durante la Guerra Civil en Euskadi. Salamanca: Universidad de Salamanca, 2001.

Ugalde, Mercedes. Mujeres y nacionalismo vasco. Génesis y desarrollo de Emakume Abertzale Batza. 1906-1936. Leioa: UPV/EHU, 1993.

Viñao, Antonio. Escuela para todos. Educación y modernidad en la España del siglo XX. Madrid: Marcial Pons, 2004.

Zufía, Pedro. Las escuelas de barriada en Vizcaya. Bilbao: Imprenta Provincial de Vizcaya, 1930. 